\title{
Management of T1 Urothelial Carcinoma of the Bladder: What Do We Know and What Do We Need To Know?
}

\author{
Boris Gershman $^{\mathrm{a}}$, Stephen A. Boorjian ${ }^{\mathrm{a}, *}$ and Richard E. Hautmann ${ }^{\mathrm{b}}$ \\ ${ }^{a}$ Department of Urology, Mayo Clinic, Rochester, MN, USA \\ ${ }^{\mathrm{b}}$ Department of Urology, University of Ulm, Ulm, Germany
}

\begin{abstract}
T1 bladder cancer constitutes approximately 25\% of incident bladder cancers, and as such carries an important public health impact. Notably, it has a heterogeneous natural history, with large variation in reported oncologic outcomes. Optimal risk-stratification is essential to individualize patient management, targeting those at greatest risk of progression for aggressive therapies such as early cystectomy, while allowing others to safely pursue bladder-preserving approaches including intravesical bacillus Calmette-Guerrin (BCG). Current strategies for diagnosis, risk-stratification, and treatment are imperfect, but emerging technologies and molecular approaches represent exciting opportunities to advance clinical paradigms in management of this disease entity.
\end{abstract}

Keywords: T1, bladder cancer, risk-stratification, management, intravesical therapy

\section{ABBREVIATIONS}

BCG

CIS

CLE

CSS

CSM

CUETO Club Urologico Espanol de Tratamiento

Oncologico

EMDA electromotive drug administration

EORTC European Organization for the Research and Treatment of Cancer

MIBC muscle-invasive bladder cancer

NBI narrow-band imaging

NMIBC non-muscle-invasive bladder cancer

\footnotetext{
${ }^{*}$ Correspondence to: Stephen A. Boorjian, MD, Mayo Clinic, 200 First Street SW, Rochester, MN 55905, USA. Tel.: +1 5072844015 Fax: +1 507284 4951; E-mail: boorjian.stephen@mayo.edu.
}

$\begin{array}{ll}\text { OCT } & \text { optical coherence tomography } \\ \text { PDD } & \text { photodynamic diagnosis } \\ \text { RC } & \text { radical cystectomy } \\ \text { RFS } & \text { recurrence-free survival } \\ \text { RT } & \text { radiotherapy } \\ \text { TUR } & \text { transurethral resection } \\ \text { WLC } & \text { white-light cystocopy }\end{array}$

\section{INTRODUCTION}

Bladder cancer is the 9th most commonly diagnosed malignancy worldwide, responsible for an estimated 429,000 new cases and 165,000 global deaths in 2012 [1]. Incidence rates are highest in the United States (US), Europe, and Egypt [2], with bladder cancer the 5th most commonly diagnosed malignancy overall in the US [3]. From an economic standpoint, bladder cancer is associated with the greatest lifetime cost per patient of all malignancies, totaling nearly $\$ 4$ billion in 
2010 in the US $[4,5]$. Given that approximately $75 \%$ of patients present with non-muscle invasive bladder cancer (NMIBC), including nearly one quarter with $\mathrm{T} 1$ disease $[6,7], \mathrm{T} 1$ bladder cancer represents a large public health burden.

There is substantial heterogeneity among patients diagnosed with $\mathrm{T} 1$ bladder cancer, with reported 5year rates of progression to muscle invasive disease (MIBC) ranging from 5-74\% [8, 9]. This underscores the need for risk-stratification to individualize patient management, especially considering that progression to MIBC is associated with adverse prognosis, with reported long-term cancer-specific survival in such cases as low as $35 \%$ [10]. The purpose of this article is therefore to review the epidemiology, natural history, diagnosis, risk-stratification, and treatment of $\mathrm{T} 1$ bladder cancer, with a focus on current knowledge and clinical practice, as well as consideration of emerging paradigms.

\section{METHODS}

A literature search using the MEDLINE/Pubmed database was performed to identify original articles, review articles, and editorials that included an analysis of T1 bladder cancer. The search was limited to studies published in English language. The following key words were used during the search: $\mathrm{T} 1$, urothelial cancer, bladder cancer, epidemiology, natural history, pathology, molecular biology, risk stratification, intravesical chemotherapy, transurethral resection, BCG, and radical cystectomy. Titles and abstracts were reviewed to assess relevance. The most significant papers as determined by the authors were chosen for analysis and used as the references.

\section{EPIDEMIOLOGY AND NATURAL HISTORY}

\section{Epidemiology}

T1 bladder cancer comprises approximately $25 \%$ of incident bladder cancers, and constitutes nearly onethird of the $75-80 \%$ of patients who present with NMIBC $[6,7]$. Moreover, when considering specifically high-grade NMIBC, the prevalence of T1 disease increases to about 58\% [11]. While the overall incidence of NMIBC has remained relatively stable over the last two decades, the distribution in stage has changed, with a decrease in the age-adjusted incidence of T1 disease from 6.7 to 4.6 per 100,000 person-years between 1988 and 2006 [6]. T1 disease, like other stages of bladder cancer, is more common in the elderly, with adjusted incidence rates approximately 3 -fold greater in patients over age 75 than in patients aged 55-64 [6].

\section{Natural history}

A number of studies have described oncologic outcomes for T1 disease within the context of evaluating the results from intravesical therapy [8], but few have specifically focused on reporting long-term natural history. In one SEER-Medicare study of 7410 patients with high-grade NMIBC, adjusted 5-year recurrence, progression, and cancer-specific mortality (CSM) rates for patients with $\mathrm{T} 1$ disease were $72.5 \%, 29.5 \%$, and $14.8 \%$, respectively [11]. Meanwhile, in a large single-institution report of 712 patients with high-risk NMIBC, of whom $68 \%$ had T1 disease, the progression rate was $16.8 \%$ at a median of 17.2 months, and the CSM rate was $22.6 \%$ at a median of 28 months for patients with $\mathrm{T} 1$ disease [12]. The longest reported follow-up to date is from Cookson et al., who described 15-year outcomes in 86 patients with high-risk NMIBC, of whom $44 \%$ had T1 disease [13]. At a median of 7.3 years of follow-up, 53\% experienced disease progression and 36\% underwent RC, with corresponding 10- and 15-year cancer-specific survival (CSS) rates of $70 \%$ and $63 \%$, respectively [13]. Unfortunately, the documented natural history of T1 disease is heterogeneous both among and within studies, which likely reflects differences between study populations as well as the temporal evolution in management approach. For example, the increased use of re-resection over time may have improved staging, and thereby resulted in a Will-Rogers effect of disparate noted rates of progression.

Importantly, progression from NMIBC to muscleinvasive disease has been associated with a worse prognosis than presentation with incident MIBC [14, 15]. Specifically, in one study of 74 patients who progressed to MIBC versus 89 matched controls, the 3 -year CSS was $37 \%$ versus $63 \%$, respectively [14]. In another study of 190 patients who progressed to and 481 who presented with MIBC, 5-year CSS was 52.9\% versus $62.4 \%$, respectively, and progression was independently associated with increased CSM (HR 2.38) [15]. Indeed, a systematic review noted that progression to MIBC was associated with a long-term DSS of only 35\% [10]. Potential etiologies for the noted adverse prognosis among NMIBC which progresses to MIBC include initial under-staging of disease, as well 
as a more aggressive tumor biology of tumors demonstrating interval pathologic progression. Overall, then, the significant heterogeneity in the biologic behavior of $\mathrm{T} 1$ disease, together with the poor prognosis in the setting of progression to MIBC, highlight the need for optimal risk-stratification.

\section{DIAGNOSIS AND STAGING}

\section{Restaging transurethral resection}

Restaging transurethral resection (TUR), within 2-6 weeks of initial resection, is an essential component in the evaluation of $\mathrm{T} 1$ bladder cancer, as it has been shown to increase staging accuracy, eradicate residual tumor, enhance response to intravesical therapy, and improve oncologic outcomes [7, 16, 17]. Re-resection is particularly important given noted variation in the quality of TUR [18, 19], as evidenced by the frequency of persistent disease at the time of repeat evaluation, as well as the rate of subsequent upstaging to MIBC, which has been reported in up to $40 \%$ of $\mathrm{T} 1$ patients [20]. Indeed, in a meta-analysis of 15 studies, the pooled prevalence for residual tumor was $47 \%$ for patients with T1 disease [21]. The quality of TUR may also be assessed by the presence of muscularis propria in the specimen, as the risk of upstaging increases when muscularis propria is absent from the initial resection specimen. Specifically, the rates of upstaging to T2 disease have been reported to be $49 \%$ versus $14 \%$ when muscularis propria is absent versus present in the initial specimen, respectively [22].

Restaging TUR also has prognostic implications, as the presence of residual tumor is associated with higher recurrence and progression risks. In one study, recurrence rates were $33 \%, 57 \%, 75 \%$, and $87.5 \%$ with $\mathrm{T} 0$, Ta, Tis, and T1 disease at restaging TUR, respectively [23]. In other series, 5-year progression rates of $82 \%$ versus $19 \%$ were noted for those with and without residual T1 [24], and 5-year CSMs of 8\%, 10\%, and $44 \%$ for restaging pathology of $<\mathrm{T} 1, \mathrm{~T} 1$, and $\mathrm{T} 2$, respectively [25]. Furthermore, the absence of residual tumor before induction BCG has been correlated with improved response to intravesical therapy, with lower rates of subsequent recurrence (11.4\% versus $27.7 \%$ ) and progression (5.7\% versus $17.0 \%$ ) [26]. Meanwhile, in a separate study, restaging TUR followed by intravesical BCG was associated with a decrease in progression from $43 \%$ to $8 \%$ for T1 tumors [27].

Interestingly, restaging TUR has itself been independently associated with a decrease in recurrence and progression risks. That is, in a randomized trial of restaging TUR for T1 bladder cancer [28], performance of a repeat TUR decreased the 5-year recurrence rate from $68 \%$ to $41 \%$ and the progression rate from $21 \%$ to $7 \%$.

\section{Novel technologies to improve TUR for T1 disease}

\section{Photo dynamic diagnosis (PDD)}

Given the demonstrated variability in the quality of TUR [18, 19, 29], new cystoscopic technologies have emerged in an effort to improve upon the limitations of conventional white-light cystoscopy (WLC). For example, photodynamic diagnosis (PDD) using 5aminolevulinic acid (5-ALA) or hexylaminolevulinic acid (HAL) fluorescence cystsocopy (FC) has been compared with WLC now in several randomized trials, with a noted reduction in residual tumor rates from $25.2-59.4 \%$ to $4.5-38.5 \% \%$ [30-32]. A recent metaanalysis found that PDD was associated with detection of $20 \%$ more tumors and a concomitant $20 \%$ absolute reduction in residual tumor rates at restaging TUR [33].

The reduction in residual tumor rates with PDD has translated into improved recurrence-free survival(RFS) for patients with NMIBC. That is, several randomized trials have compared RFS with FC-TUR versus WLCTUR, and have noted an improvement in RFS with FC-TUR [30, 34-36]. Admittedly, the impact on progression has been mixed. Specifically, in one study, the progression rate was decreased from $18 \%$ to $8 \%$ [35], but in a separate subset analysis examining HGT1 tumors, progression was not significantly different (19\% versus $12 \%$ for FC and WLC, respectively) [37].

\section{Narrow band imaging (NBI)}

Narrow band imaging utilizes filtered light at $415 \mathrm{~nm}$ and $540 \mathrm{~nm}$ bands, which is preferentially absorbed by hemoglobin, to provide improved visualization of surface vasculature [38]. Unlike PDD, NBI does not require instillation of a fluorescent intravesical agent. Although not specific for T1 tumors, studies have noted an overall improved detection rate for bladder tumors [39] and reduced recurrence rate when office fulguration is performed with NBI [40]. A meta-analysis of 1022 patients from 8 studies [41] determined that NBI was associated with an improved sensitivity compared with WLC ( $85 \%$ versus $94 \%$ ) but no difference in specificity $(85 \%$ and $87 \%$ for NBI and WLC, respectively) [41]. One randomized trial has reported a decrease in the 2-year recurrence rate from $33 \%$ to $22 \%$, although this did not reach statistical significance $(p=0.05)$ [42]. An ongoing randomized, international trial will provide additional data regarding recurrence rates with NBI-TUR [38]. 
Optical coherent tomography (OCT)

Optical coherence tomography (OCT) is a novel endoscopic imaging modality that uses near-infrared light to generate cross-sectional images of the bladder surface to a depth of 1-2 mm [38]. An early investigation reported $100 \%$ sensitivity and $90 \%$ specificity for detection of muscle-invasive disease [43]. As such, this technology has the potential to markedly reduce the rate of upstaging of $\mathrm{T} 1$ tumors. The addition of OCT to FC has also been shown to provide a significant improvement in diagnosing bladder cancer compared to FC or WLC alone, with a per-patient sensitivity of $100 \%$ and specificity of $87.5 \%$ [44]. A recently completed multi-institutional trial will offer additional data regarding the diagnostic accuracy of OCT [38].

\section{Confocal laser endomicroscopy (CLE)}

Confocal laser endomicroscopy (CLE) is another emerging technology has the ability to provide realtime visualization with microscopic resolution [38]. It uses a $488 \mathrm{~nm}$ laser to scan flourescein-stained tissue, delivering micron-scale images [45]. In vivo data is limited, but two early studies have demonstrated significant endomicroscopic imaging differences between benign lesions, low-grade tumors, and high-grade [46, 47].

\section{En bloc resection}

En bloc resection, which consists of removing an entire tumor in one piece, aims to enhance diagnostic accuracy and provide an oncologic benefit through complete resection without spillage of tumor cells [48]. Originally described using monopolar electrocautery [49], it has also been performed using laser resection [50-52], and with a water-jet-aided hydrodissection technique for larger tumors [53]. Oncologic outcomes are currently under investigation in a randomized trial [54].

Collectively, these novel imaging technologies and resection techniques have the potential to improve upon the quality of traditional white-light TUR. Such approaches may enhance the accuracy of staging, allow for a more complete resection, and ultimately impact the natural history of $\mathrm{T} 1$ disease with reduced recurrence and/or progression.

\section{RISK-STRATIFICATION \& PROGNOSIS}

\section{Traditional risk-stratification}

Given the documented heterogeneity in the natural history of $\mathrm{T} 1$ bladder cancers, risk-stratification is essential for individualizing patient management. Ideal prognostic factors would identify those patients who may be safely managed with local therapy (i.e. transurethral resection plus intravesical therapy), and differentiate patients who are at high risk of progression and would therefore most benefit from aggressive treatment (i.e. early cystectomy). For the majority of clinicians, risk-stratification of $\mathrm{T} 1$ tumors currently relies on standard pathologic variables. Kulkarni et al. [8] provide a nice summary of these features, including the presence of associated CIS, tumor multifocality, hydronephrosis, tumor size $>3 \mathrm{~cm}$, deep lamina propria invasion, and residual T1 on restaging TUR.

The presence of lymphovascular invasion (LVI) represents a particularly important adverse prognostic feature in NMIBC [55], as this entity has been associated with increased risks of progression, metastasis [56], and inferior survival outcomes [57, 58]. Indeed, a meta-analysis that included four studies evaluating LVI in 1557 patients with HGT1 tumors demonstrated that LVI was associated with recurrence, progression, and cancer-specific mortality [59]. As such, these patients may in particular benefit from upfront cystectomy. Meanwhile, the presence of histologic variants of urothelial carcinoma have also been found to confer adverse prognosis [60], with increased rates of locallyadvanced tumor stage both at TURBT and RC [61, 62] and higher rates of progression [63].

Two scoring systems have been developed in an effort to refine risk-stratification (Table 1). The EORTC risk tables were created from a pooled analysis of 2596 patients with $\mathrm{Ta} / \mathrm{T} 1 \mathrm{NMIBC}$ from 7 EORTC trials, including 1108 patients with T1 disease [9]. A separate risk-stratification system was created by the Club Urologico Espanol de Tratamiento Oncologico (CUETO) collaborative group using pooled data from 1062 BCGtreated patients in 4 trials, including 848 with $\mathrm{T} 1$ disease $[64,65]$. Notably, although theEORTC and CUETOrisk scores improve risk-stratification by quantifying recurrence and progression probabilities, their performance remains imperfect. That is, in a multi-institutional external validation study of 4689 patients, both risk scores had poor discrimination (c-index 0.52-0.66), with both overestimating the risk of progression for high-risk patients [66]. Similarly, in a separate small study of incident T1 tumors, EORTC risk category was not associated with recurrence or progression [67]. In particular, differences in study populations should be considered when applying the risk scores. For example, few patients in the EORTC analysis were treated with intravesical BCG, and, accordingly, the EORTC risk tables overestimated recurrence and progression risk in the 
Table 1a

EORTC and CUETO risk scoring models. Separate scores for recurrence and progression are calculated by adding points for presence of risk factors

\begin{tabular}{|c|c|c|c|}
\hline \multirow[t]{2}{*}{ Model } & \multirow[t]{2}{*}{ Risk Factors } & \multicolumn{2}{|c|}{ Points } \\
\hline & & Recur & Prog \\
\hline \multirow[t]{15}{*}{ EORTC [9] } & 1. Number of tumors & & \\
\hline & 1 & 0 & 0 \\
\hline & 2 to 7 & 3 & 3 \\
\hline & $\geq 8$ & 6 & 3 \\
\hline & 2. Tumor size $\geq 3 \mathrm{~cm}$ & 3 & 3 \\
\hline & 3. Prior recurrence & & \\
\hline & None & 0 & 0 \\
\hline & $\leq 1$ per year & 2 & 2 \\
\hline & $>1$ per year & 4 & 2 \\
\hline & 4. Stage T1 & 1 & 4 \\
\hline & 5. Concomitant CIS & 1 & 6 \\
\hline & 6. Grade & & \\
\hline & Grade 1 & 0 & 0 \\
\hline & Grade 2 & 1 & 0 \\
\hline & Grade 3 & 2 & 5 \\
\hline \multirow[t]{13}{*}{ CUETO [64] } & 1. Female gender & 3 & 0 \\
\hline & 2. Age & & \\
\hline & $<60$ & 0 & 0 \\
\hline & $60-70$ & 1 & 0 \\
\hline & $>70$ & 2 & 2 \\
\hline & 3. Recurrent tumor & 4 & 2 \\
\hline & 4. $\geq 4$ tumors & 2 & 1 \\
\hline & 5. Stage T1 & 0 & 2 \\
\hline & 6. Concomitant CIS & 2 & 1 \\
\hline & 7. Grade & & \\
\hline & Grade 1 & 0 & 0 \\
\hline & Grade 2 & 1 & 2 \\
\hline & Grade 3 & 3 & 6 \\
\hline
\end{tabular}

CUETO cohort, which consists of BCG-treated patients [68]. Such observations highlight the importance of validating risk-stratification tools. While other risk prediction tools have been developed as well, including a nomogram based on a multi-institutional cohort [69], these have not been widely adopted and likewise require external validation.

\section{Pathologic substaging}

Pathologic substaging has been proposed as an approach to more accurately risk-stratify $\mathrm{T} 1$ tumors.
Specifically, T1 tumors have been sub-classified as T1a, $\mathrm{T} 1 \mathrm{~b}$, or T1c, based on invasion above, into, or beyond the muscularis mucosa-vascular plexus (Figs. 1-3). A number of studies, dating back to the early 1990s, support an adverse prognostic impact of greater depth of invasion [70-77]. More recently, a meta-analysis highlighted the prognostic value of pathologic substaging [59]. That is, Martin-Doyle et al. [59] evaluated 15,215 patients from 73 studies, of whom $97.9 \%$ had HGT1 disease. T1b/c substage, which was evaluated in 11 studies of 1,431 patients, was identified as the greatest risk factor for progression (HR 3.34) and CSM (HR 2.02). The authors thereby suggested a modification to the TNM classification to incorporate this feature.

Unfortunately, however, the muscularis mucosavascular plexus may not be evident in up to one-third of cases [78], precluding pathologic substaging. Accordingly, other pathologic substaging systems have been proposed based on the depth of invasion measured in $\mathrm{mm}$ [76]. Indeed, one group described a substaging system that dichotomized $\mathrm{T} 1$ into microinvasive (T1mic, depth $\leq 0.5 \mathrm{~mm}$ ) and extensive (T1ext, depth $>0.5 \mathrm{~mm}$ ) [79]. This classification system predicted progression and DSS in a single study [80], and was superior to the EORTC risk score and molecular markers for predicting progression in another analysis [67]. Nevertheless, the practice of quantifying the depth of invasion for $\mathrm{T} 1$ tumors has not to date been widely adopted.

\section{Molecular, genomic, and epigenomic classification}

In light of the limitations of standard clinicopathologic features as prognostic variables for patients with T1 disease, it is clear that a need exists for more refined risk-stratification. In this regard, there has been a growing effort to develop a molecular classification of bladder cancer.

Early reports noted an association between immunohistochemical (IHC) expression of cell cycle markers

Table $1 b$

Estimated probabilities of recurrence and progression at 1- and 5-years from the EORTC and CUETO models

\begin{tabular}{|c|c|c|c|c|c|c|c|c|}
\hline \multirow[t]{2}{*}{ Model } & \multicolumn{4}{|c|}{ Recurrence } & \multicolumn{4}{|c|}{ Progression } \\
\hline & Score & $\begin{array}{c}\text { 1-yr } \\
\text { Probability }\end{array}$ & $\begin{array}{c}5-\mathrm{yr} \\
\text { Probability }\end{array}$ & C-index & Score & $\begin{array}{c}1-y r \\
\text { Probability }\end{array}$ & $\begin{array}{c}5-\mathrm{yr} \\
\text { Probability }\end{array}$ & C-index \\
\hline \multirow[t]{4}{*}{$\overline{\text { EORTC [9] }}$} & 0 & $15 \%$ & $31 \%$ & 1-yr: 0.66 & 0 & $0.2 \%$ & $0.8 \%$ & 1-yr: 0.74 \\
\hline & $1-4$ & $24 \%$ & $46 \%$ & 5-yr: 0.66 & $2-6$ & $1 \%$ & $6 \%$ & 5-yr: 0.75 \\
\hline & $5-9$ & $38 \%$ & $62 \%$ & & $7-13$ & $5 \%$ & $17 \%$ & \\
\hline & $\geq 10$ & $61 \%$ & $78 \%$ & & $\geq 14$ & $17 \%$ & $45 \%$ & \\
\hline \multirow{4}{*}{ CUETO [64] } & $\overline{0}-4$ & $8 \%$ & $21 \%$ & 1-yr: 0.64 & $0-4$ & $1 \%$ & $4 \%$ & 1-yr: 0.69 \\
\hline & $5-6$ & $12 \%$ & $36 \%$ & 5-yr: 0.64 & $5-6$ & $3 \%$ & $12 \%$ & 5-yr: 0.70 \\
\hline & $7-9$ & $25 \%$ & $48 \%$ & & $7-9$ & $6 \%$ & $21 \%$ & \\
\hline & $\geq 10$ & $42 \%$ & $68 \%$ & & $\geq 10$ & $14 \%$ & $34 \%$ & \\
\hline
\end{tabular}




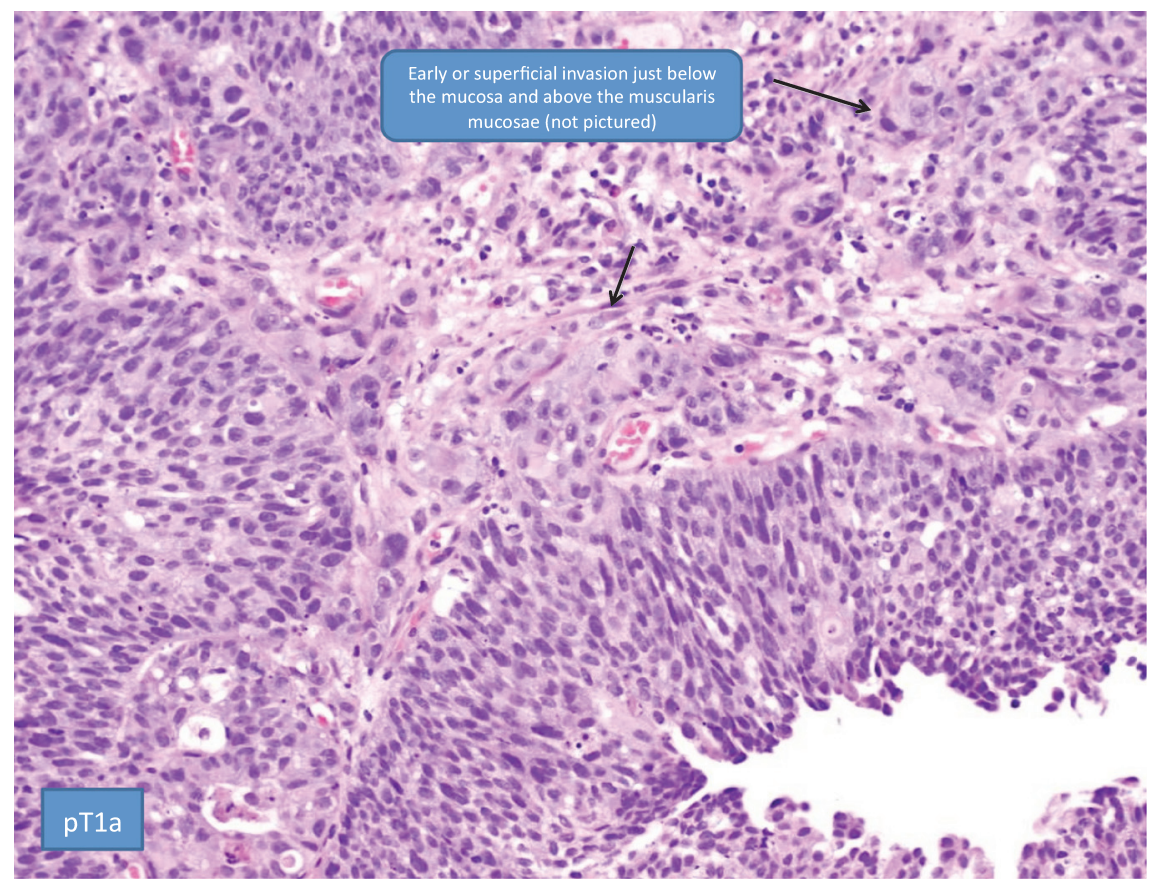

Fig. 1. Pathologic substaging - pT1a denotes early or superficial tumor invasion below the mucosa but above the muscularis mucosae.

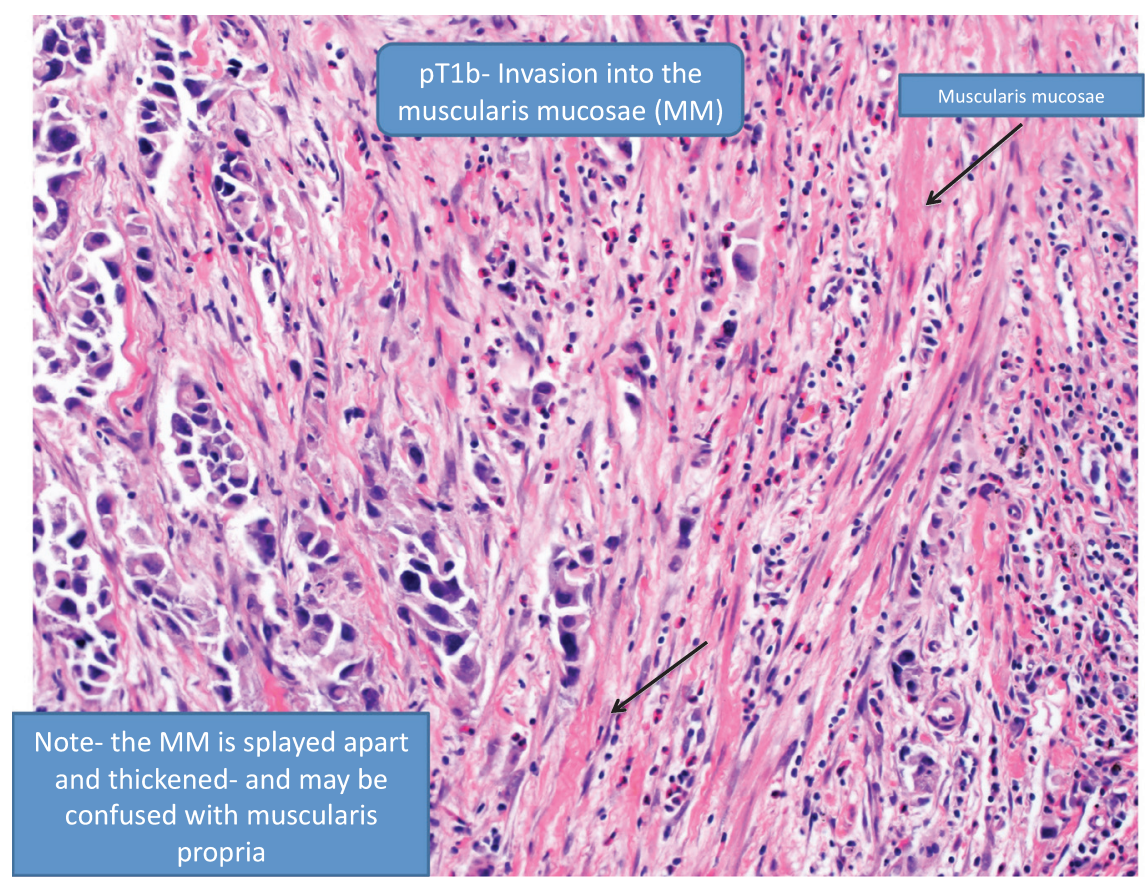

Fig. 2. Pathologic substaging - pT1b denotes tumor invasion into the muscularis mucosae.

such p53, pRB, and p16 and outcomes following RC [81], and suggested a potential prognostic role based on expression in TUR specimens [82]. Subsequent reports found an association with recurrence and CSM for NMIBC [83], and specifically T1 tumors [84], although other investigations have not confirmed these findings [85]. As such, the search for novel molecular markers remains ongoing. For instance, a multi-national validation study noted that a 4-protein classifier (including cyclin D1, MCM7, TRIM29, and UBE2C) was 


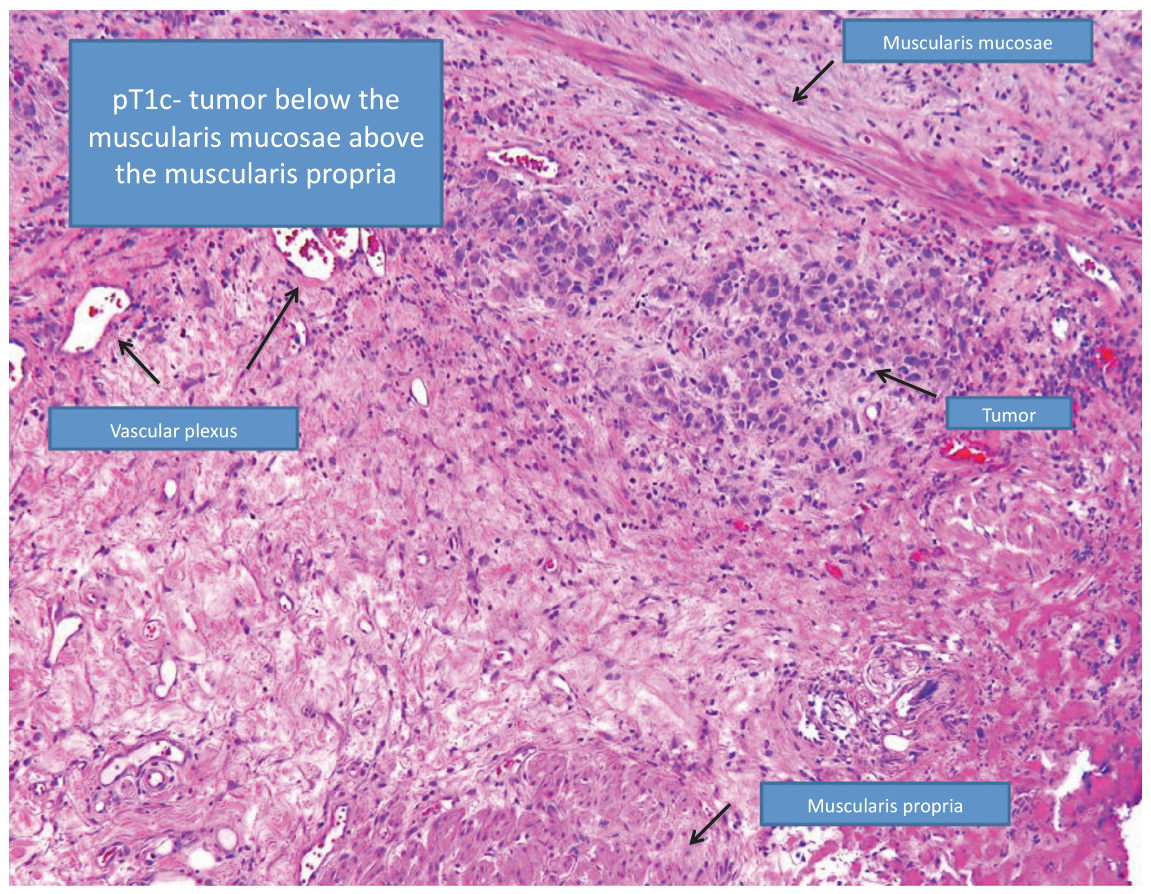

Fig. 3. Pathologic substaging - pT1c denotes tumor invasion below the muscularis mucosae but above the muscularis propria.

associated with progression-free survival for patients with $\mathrm{Ta} / \mathrm{T} 1$ tumors [86].

At the same time, the dissemination of highthroughput genetic sequencing technology has greatly accelerated the development of a molecular framework for bladder cancer. Genomic classifiers (GC) derived from such data have been found to contain significant prognostic value, as illustrated by one GC that was highly correlated with PFS and CSS [87]. Genomic data may also reveal the underlying biology behind traditional clinicopathologic risk factors, as in the case of specific genomic alterations that have been correlated with pathologic substaging [88]. Epigenetic alterations have likewise been examined, with several studies correlating epigenetic changes with PFS and CSS for HGT1 tumors [89] as well as with progression in Ta tumors [90].

One group has as well attempted to translate molecular characterization of NMIBC subtypes into a classification system based on histology and IHC [91]. These authors correlated gene expression profiling of NMIBC tumors with IHC features to describe three distinct subtypes: urobasal (Uro), genomically unstable (GU), and squamous cell carcinoma-like (SCCL) [92-94]. In a validation study in which this molecularpathologic classification was applied to $167 \mathrm{~T} 1$ tumors, GU/SCCL subtypes were associated with an increased risk of progression, identifying $82 \%$ of those who progressed within 3-years [91]. While this approach requires further external validation and quantification of its incremental prognostic value over standard prognostic variables, it demonstrates potential future paradigms for risk-stratification that rely on genomic and molecular data.

Overall, it is evident that current risk-stratification based on standard clinicopathologic features remains imperfect. Future paradigms may combine novel pathologic and molecular frameworks to individualize prognosis and thereby guide patient counseling.

\section{TREATMENT}

\section{Immediate intravesical chemotherapy after TUR}

While a dose of intravesical chemotherapy within 24 hours of TUR has been advocated for patients with NMIBC to prevent recurrence $[8,16,17]$, there is conflicting evidence to support this approach for T1 tumors. One meta-analysis of 7 randomized trials of patients with $\mathrm{Ta} / \mathrm{T} 1$ tumors, including $32 \%$ with T1 tumors, noted an absolute decrease of $11.7 \%$ in recurrence with immediate intravesical chemotherapy compared to TUR alone [95], and a more recent meta-analysis of 3103 patients noted a 13\% absolute risk reduction for recurrence, with a similar benefit for patients with high-risk features, including 
T1 tumors [96]. On the other hand, a randomized trial of intravesical epirubicin found no benefit for intermediate/high-risk tumors [97]. Notably, moreover, immediate intravesical chemotherapy utilization remains highly limited in clinical practice [98, 99], likely for a variety of reasons, and overall its place in the management of $\mathrm{T} 1$ tumors has not been established.

\section{Intravesical BCG therapy}

Multiple meta-analyses support the superiority of BCG over TUR alone or TUR with intravesical chemotherapy in reducing recurrence and progression of NMIBC (Table 2) [100-106]. Specifically, BCG has been associated with a 39-70\% reduction in recurrence and $27-34 \%$ reduction in progression, although of note the benefit of treatment has often been restricted to studies using maintenance BCG [100-106]. For patients with $\mathrm{T} 1$ tumors in particular, the use of BCG after TUR has been noted to result in a subsequent rate of recurrence ranging from $21-70 \%$, progression in $5-49 \%$, and disease-specific survival in $59-100 \%$ [107]. As such, multiple guidelines support the use of BCG for patients with T1 disease [7, 16].

Nevertheless, the optimal duration and dosing of BCG remains in debate [108] and it must be emphasized as well that the bulk of data from which these recommendations are derived were generated from cohorts of NMIBC patients rather than specifically T1 patients alone. The SWOG 8507 study, which included patients with Ta, T1, and CIS disease, demonstrated that 3-years of maintenance BCG was associated with decreased recurrence and progression compared to a 6week induction course alone [109]. Notably, only $16 \%$ of patients in that trial received all maintenance doses due to toxicity [109], and methodological concerns about the study have since been raised [108]. At the same time, in the EORTC 30962 trial of 1-year versus 3-years of BCG, which was likewise conducted in patients with NMIBC, a reduction in recurrence was seen only among high-risk (T1 and/or G3) patients treated for 3-years [110]. No difference in recurrence between the cohorts was noted for intermediate-risk patients, and no difference in progression was found for either risk group [110]. Similarly, the CUETO 98013 trial, conducted in patients with CIS, TaG3, or T1G3 tumors of the bladder, observed no benefit to 3-year maintenance BCG compared to a standard induction course with regard to recurrence or progression [111]. However, the recurrence and progression rates in the CUETO trial [111] were lower than anticipated, which may reflect improved identification of patients for early cystectomy and a reduced benefit from maintenance BCG.

Further contributing to the debate over maintenance BCG has been the publication of results from an alternate paradigm for patients with a complete response to induction BCG, consisting of surveillance and the utilization of a repeat induction course for patients who relapse [112]. Indeed, the reported 5-year recurrence and progression rates with this approach of $54 \%$ and $11 \%$ [112] are comparable to the outcomes with maintenance BCG in the SWOG 8507 study [109].

\section{Early cystectomy}

Immediate cystectomy represents an important management option for patients with T1 disease [7, 16, 17]. In particular, up-front cystectomy has been advocated for patients assessed to be at greatest risk of progression $[7,16,17]$. The evidence for early cystectomy in high-risk NMIBC is several-fold. First, long-term

Table 2

Meta-analyses evaluating intravesical BCG therapy for patients with NMIBC

\begin{tabular}{|c|c|c|c|c|c|c|c|}
\hline Study & $\begin{array}{l}\text { \# studies } \\
\text { included } \\
(\# \mathrm{RCT})\end{array}$ & \# pts & $\begin{array}{l}\text { Control } \\
\text { arm }\end{array}$ & Recurrence & Progression & CSM & $\begin{array}{l}\text { Maintenance } \\
\text { BCG Effect } \\
\text { Modification }^{5}\end{array}$ \\
\hline Shelley 2001 [103] & $6(6)$ & 585 & TUR alone & OR $0.30^{1}$ HR 0.44 & - & - & - \\
\hline Sylvester 2002 [106] & $24(24)$ & 4863 & $\begin{array}{l}\text { TUR } \pm \text { other } \\
\text { intravesical therapy }\end{array}$ & - & OR $0.73^{2}$ OR $0.63^{3}$ & N.S. & Yes \\
\hline Bohle 2003 [105] & $11(8)$ & 2749 & TUR + mitomycin C & OR $0.56^{2}$ OR $0.42^{3}$ & - & - & Yes \\
\hline Bohle 2004 [100] & $9(7)$ & 2410 & $\mathrm{TUR}+$ mitomycin $\mathrm{C}$ & - & N.S. ${ }^{2}$ OR $0.66^{3}$ & - & Yes \\
\hline Shelley 2004 [104] & $6(6)$ & 1527 & $\mathrm{TUR}+$ mitomycin C & N.S. ${ }^{2}$ HR $0.69^{4}$ & N.S. & - & - \\
\hline Han 2006 [101] & $25(25)$ & 4767 & $\begin{array}{l}\text { TUR } \pm \text { other } \\
\text { intravesical therapy }\end{array}$ & OR $0.61^{2}$ OR $0.47^{3}$ & - & - & Yes \\
\hline Malmstrom 2009 [102] & $9(9)$ & 2820 & $\mathrm{TUR}+$ mitomycin $\mathrm{C}$ & N.S. ${ }^{2}$ HR $0.68^{3}$ & N.S. & N.S. & Yes \\
\hline
\end{tabular}

“_”: not evaluated. N.S. = not statistically significantly different. ${ }^{1}$ For recurrence at 12 months. ${ }^{2}$ All studies within the meta-analysis. ${ }^{3}$ Studies with maintenance BCG within the meta-analysis. ${ }^{4}$ Studies of high-risk tumors within the meta-analysis. ${ }^{5}$ Benefit in studies with maintenance BCG but not in studies without maintenance BCG. 
Table 3

Observational studies comparing immediate or early RC versus delayed RC for T1 bladder cancer ${ }^{1}$

\begin{tabular}{|c|c|c|c|c|c|c|}
\hline \multirow[t]{2}{*}{ Study } & \multirow[t]{2}{*}{ Cohorts } & \multicolumn{2}{|c|}{ Early RC } & \multicolumn{2}{|c|}{ Delayed RC } & \multirow[t]{2}{*}{$p$-value } \\
\hline & & CSS & OS & CSS & OS & \\
\hline $\operatorname{Herr}(2001)^{2}$ [115] & $\begin{array}{l}\text { Early RC: } N=48^{3} / 32^{4} \\
\text { Delayed RC: } N=42^{3} / 58^{4}\end{array}$ & $\begin{array}{l}\text { 15-yr: } \\
69^{3} \% / 75^{4} \%\end{array}$ & - & $\begin{array}{l}\text { 15-yr: } \\
26^{3} \% / 34^{4} \%\end{array}$ & - & $\begin{array}{l}\mathrm{CSS}^{3}: 0.003 \\
\mathrm{CSS}^{4}: 0.001\end{array}$ \\
\hline Denzinger (2007) [114] & $\begin{array}{l}\text { Early RC: } N=54 \\
\text { Delayed RC: } N=51\end{array}$ & 10-yr: $78 \%$ & - & 10-yr: $51 \%$ & - & CSS: $<0.01$ \\
\hline Hautmann (2009) [118] & $\begin{array}{l}\text { Early RC: } N=175 \\
\text { Delayed RC: } N=99\end{array}$ & 10-yr: $79 \%$ & - & 10-yr: $65 \%$ & - & None provided \\
\hline De Berardinis (2011) [117] & $\begin{array}{l}\text { Early RC: } N=72 \\
\text { Delayed RC: } N=80\end{array}$ & 10-yr: $78 \%$ & 10-yr: $43 \%$ & 10-yr: $78 \%$ & 10-yr: $58 \%$ & $\begin{array}{l}\text { CSS: } 0.98 \\
\text { OS: } 0.049\end{array}$ \\
\hline
\end{tabular}

“_“: not evaluated. ${ }^{1}$ Criteria to define "early" and "delayed” RC varied by study. ${ }^{2}$ Included high-grade Ta and T1. ${ }^{3} \mathrm{RC}$ within 2 years of initial BCG. ${ }^{4} \mathrm{RC}$ within 1 year of initial BCG.

data indicate high progression and CSM rates for T1 disease [13], supporting early cystectomy especially in younger patients. In addition, observational studies have demonstrated inferior oncologic outcomes for patients who progress to MIBC from NMIBC compared to those who present with de novo MIBC [10, 14, 15]. Likewise, patients who are upstaged from NMIBC to pT2 at the time of cystectomy have poorer RFS than correctly staged patients with pT2 disease [113]. Moreover, studies have noted superior survival for patients with G3T1 bladder cancer who undergo early cystectomy compared to deferred cystectomy (Table 3) [8, 114-118]. For instance, Denzinger et al. noted that of 105 patients with high-risk G3T1 tumors who were offered early cystectomy, 10 -year CSS was $78 \%$ in the early cystectomy group versus $51 \%$ with deferred cystectomy [114]. In another study, introduction of early $\mathrm{RC}$ for high-risk T1 tumors in a contemporary cohort was associated with a reduction in 5-year CSM from $48 \%$ to $31 \%$ compared to historical controls [116]. In fact, the increased use of intravesical therapy for HGT1 tumors has been correlated with decreasing CSS after cystectomy [119]. Similarly, an increase in the prevalence of lymph node metastases at cystectomy has been correlated with increasing number of prior TURs, from $8 \%$ in patients who had undergone a single TUR, to $24 \%$ in those who had undergone 2-4 TURs [120].

There are several potential explanations for the noted survival benefit of early cystectomy, including addressing understaging and preventing the development of disseminated disease during local therapy. Taken together, evidence supports consideration of immediate or early cystectomy for patients with $\mathrm{T} 1$ disease, particularly in younger patients and in those with clinicopathologic risk factors for disease progression. Nevertheless, it must be acknowledged that the data supporting early cystectomy for HGT1 tumors are from retrospective series, and thus subject to considerable potential bias. As such, the optimal management of T1 disease requires an individualized approach to balance the risks of RC against the potential survival benefit, particularly in light of the morbidity of RC [121].

\section{Bladder-sparing therapy for T1 tumors}

Radiation therapy (RT) has been explored as a bladder-preserving alternative to early cystectomy for patients with T1 tumors. In one trial, 210 patients with G3T1 disease were treated with RT or TUR with/without intravesical therapy [122]. No difference in progression or overall survival was noted, although patients did not routinely undergo restaging TUR, and local failure rates were high [122]. In contrast, an observational study of 141 patients with high-risk T1 treated with RT or chemoradiotherapy noted complete response in $88 \%$ at post-treatment restaging TUR, and CSS of $82 \%$ and $73 \%$ at 5- and 10-years [123].

Partial cystectomy also represents an alternative to RC for appropriately selected patients with $\mathrm{T} 1$ tumors, including tumors located within a diverticulum or solitary tumors without concomitant CIS [124]. Contemporary series $[125,126]$ and matched analyses [127, 128] have reported comparable survival outcomes with partial cystectomy to RC in carefully selected patients.

\section{Future directions in the treatment of $T 1$ disease}

The development of novel intravesical therapies represents an important area of active research for $\mathrm{T} 1$ disease. Intravesical gemcitabine, for example, has now been evaluated in several randomized trials. A meta-analysis of 6 trials noted that gemcitabine was superior to intravesical BCG for reducing recurrence in the setting of prior BCG-failure, but was not associated with lower recurrence or progression rates in 
BCG-naïve patients [129]. Intravesical docetaxel also appears to have activity in BCG-failures [130]. Viral vector-based therapies hold promise, with a phase 1 study of intravesical adenovirus-mediated interferon$\alpha 2 b$ demonstrating activity in the setting of BCG failures [131].

Another area of current investigation involves improving drug-delivery mechanisms [132]. Microwave-induced hyperthermia is designed to improve delivery of intravesical agents, most commonly mitomycin C [133]. A systematic review of 22 trials, including a meta-analysis of 4 trials, noted a $59 \%$ relative reduction in the risk of recurrence with chemohyperthermia, and a potential benefit in the setting of failed BCG therapy [133]. Electromotive drug administration (EMDA) is another approach to improve delivery of intravesical agents. Several randomized trials have demonstrated improved outcomes for electromotive mitomycin $\mathrm{C}$ administration compared with passive administration [134, 135], and have suggested a benefit in combination with BCG [136]. Nanoparticles represent another novel delivery vehicle, and have been used to deliver saRNA [137], docetaxel [138], and paclitaxel [139] to bladder tumors.

Future paradigms are likely to include both novel intravesical agents and drug delivery mechanisms to improve the bladder-preserving treatment options for T1 patients.

\section{CONCLUSION}

T1 bladder cancer represents a heterogeneous disease state with varied reported oncologic outcomes. Accordingly, optimal risk-stratification is essential to individualize patient management. Current strategies for diagnosis, risk-stratification, and treatment are imperfect, but emerging technologies and molecular data represent exciting opportunities to advance clinical paradigms in the management of this challenging entity.

\section{ACKNOWLEDGMENTS}

None.

\section{AUTHOR CONTRIBUTIONS}

B Gershman: Protocol/project development, Manuscript writing/editing.

SA Boorjian: Protocol/project development, Manuscript writing/editing.
RE Hautmann: Protocol/project development, Manuscript writing/editing.

\section{CONFLICT OF INTEREST}

The authors have no conflicts of interest to report.

\section{REFERENCES}

[1] Ferlay J, Soerjomataram I, Dikshit R, et al. Cancer incidence and mortality worldwide: Sources, methods and major patterns in GLOBOCAN 2012. Int $\mathrm{J}$ Cancer 2015;136(5):E359-86.

[2] Chavan S, Bray F, Lortet-Tieulent J, Goodman M, Jemal A. International variations in bladder cancer incidence and mortality. Eur Urol 2014;66(1):59-73.

[3] Siegel R, Ma J, Zou Z, Jemal A. Cancer statistics, 2014. CA Cancer J Clin 2014;64(1):9-29.

[4] Mossanen M, Gore JL. The burden of bladder cancer care: Direct and indirect costs. Curr Opin Urol 2014;24(5): 487-91.

[5] Riley GF, Potosky AL, Lubitz JD, Kessler LG. Medicare payments from diagnosis to death for elderly cancer patients by stage at diagnosis. Med Care 1995;33(8):828-41.

[6] Nielsen ME, Smith AB, Meyer AM, et al. Trends in stage-specific incidence rates for urothelial carcinoma of the bladder in the United States: 1988 to 2006. Cancer 2014;120(1):86-95.

[7] Clark PE, Agarwal N, Biagioli MC, et al. Bladder cancer. J Natl Compr Canc Netw 2013;11(4):446-75.

[8] Kulkarni GS, Hakenberg OW, Gschwend JE, et al. An updated critical analysis of the treatment strategy for newly diagnosed high-grade T1 (previously T1G3) bladder cancer. Eur Urol 2010;57(1):60-70.

[9] Sylvester RJ, van der Meijden AP, Oosterlinck W, et al. Predicting recurrence and progression in individual patients with stage Ta T1 bladder cancer using EORTC risk tables: A combined analysis of 2596 patients from seven EORTC trials. Eur Urol 2006;49(3):466-5; discussion 75-7.

[10] van den Bosch S, Alfred Witjes J. Long-term cancer-specific survival in patients with high-risk, non-muscle-invasive bladder cancer and tumour progression: A systematic review. Eur Urol 2011;60(3):493-500.

[11] Chamie K, Litwin MS, Bassett JC, et al. Recurrence of highrisk bladder cancer: A population-based analysis. Cancer 2013;119(17):3219-27.

[12] Thomas F, Rosario DJ, Rubin N, Goepel JR, Abbod MF, Catto JW. The long-term outcome of treated high-risk nonmuscle-invasive bladder cancer: Time to change treatment paradigm? Cancer 2012;118(22):5525-34.

[13] Cookson MS, Herr HW, Zhang ZF, Soloway S, Sogani PC, Fair WR. The treated natural history of high risk superficial bladder cancer: 15-year outcome. J Urol 1997;158(1): 62-7.

[14] Schrier BP, Hollander MP, van Rhijn BW, Kiemeney LA, Witjes JA. Prognosis of muscle-invasive bladder cancer: Difference between primary and progressive tumours and implications for therapy. Eur Urol 2004;45(3):292-6.

[15] Breau RH, Karnes RJ, Farmer SA, et al. Progression to detrusor muscle invasion during urothelial carcinoma surveillance is associated with poor prognosis. BJU International 2014;113(6):900-6. 
[16] Babjuk M, Burger M, Zigeuner R, et al. EAU guidelines on non-muscle-invasive urothelial carcinoma of the bladder: Update 2013. Eur Urol 2013;64(4):639-53.

[17] Hall MC, Chang SS, Dalbagni G, et al. Guideline for the management of nonmuscle invasive bladder cancer (stages Ta, T1, and Tis): 2007 update. J Urol 2007;178(6): 2314-30.

[18] Brausi M, Collette L, Kurth K, et al. Variability in the recurrence rate at first follow-up cystoscopy after TUR in stage Ta T1 transitional cell carcinoma of the bladder: A combined analysis of seven EORTC studies. Eur Urol 2002;41(5): 523-31.

[19] Mariappan P, Zachou A, Grigor KM. Detrusor muscle in the first, apparently complete transurethral resection of bladder tumour specimen is a surrogate marker of resection quality, predicts risk of early recurrence, and is dependent on operator experience. Eur Urol 2010;57(5):843-9.

[20] Dutta SC, Smith JA, Jr., Shappell SB, Coffey CS, Chang SS, Cookson MS. Clinical under staging of high risk nonmuscle invasive urothelial carcinoma treated with radical cystectomy. J Urol 2001;166(2):490-3.

[21] Vianello A, Costantini E, Del Zingaro M, Bini V, Herr HW, Porena M. Repeated white light transurethral resection of the bladder in nonmuscle-invasive urothelial bladder cancers: Systematic review and meta-analysis. J Endourol 2011;25(11):1703-12.

[22] Herr HW. The value of a second transurethral resection in evaluating patients with bladder tumors. J Urol 1999;162(1):74-6.

[23] Brauers A, Buettner R, Jakse G. Second resection and prognosis of primary high risk superficial bladder cancer: Is cystectomy often too early? J Urol 2001;165(3):808-10.

[24] Herr HW, Donat SM, Dalbagni G. Can restaging transurethral resection of T1 bladder cancer select patients for immediate cystectomy? J Urol 2007;177(1):75-9; discussion 9.

[25] Dalbagni G, Vora K, Kaag M, et al. Clinical outcome in a contemporary series of restaged patients with clinical T1 bladder cancer. Eur Urol 2009;56(6):903-10.

[26] Guevara A, Salomon L, Allory Y, et al. The role of tumorfree status in repeat resection before intravesical bacillus Calmette-Guerin for high grade Ta, T1 and CIS bladder cancer. J Urol 2010;183(6):2161-4.

[27] Herr HW. Restaging transurethral resection of high risk superficial bladder cancer improves the initial response to bacillus Calmette-Guerin therapy. J Urol 2005;174(6): 2134-7.

[28] Divrik RT, Sahin AF, Yildirim U, Altok M, Zorlu F. Impact of routine second transurethral resection on the long-term outcome of patients with newly diagnosed pT1 urothelial carcinoma with respect to recurrence, progression rate, and disease-specific survival: A prospective randomised clinical trial. Eur Urol 2010;58(2):185-90.

[29] Herr HW, Donat SM. Quality control in transurethral resection of bladder tumours. BJU International 2008;102(9 Pt B):1242-6.

[30] Filbeck T, Pichlmeier U, Knuechel R, Wieland WF, Roessler W. Clinically relevant improvement of recurrence-free survival with 5-aminolevulinic acid induced fluorescence diagnosis in patients with superficial bladder tumors. J Urol 2002;168(1):67-71

[31] Kriegmair M, Zaak D, Rothenberger KH, et al. Transurethral resection for bladder cancer using 5-aminolevulinic acid induced fluorescence endoscopy versus white light endoscopy. J Urol 2002;168(2):475-8.
[32] Riedl CR, Daniltchenko D, Koenig F, Simak R, Loening SA, Pflueger H. Fluorescence endoscopy with 5-aminolevulinic acid reduces early recurrence rate in superficial bladder cancer. J Urol 2001;165(4):1121-3.

[33] Kausch I, Sommerauer M, Montorsi F, et al. Photodynamic diagnosis in non-muscle-invasive bladder cancer: A systematic review and cumulative analysis of prospective studies. Eur Urol 2010;57(4):595-606.

[34] Denzinger S, Burger M, Walter B, et al. Clinically relevant reduction in risk of recurrence of superficial bladder cancer using 5-aminolevulinic acid-induced fluorescence diagnosis: 8-year results of prospective randomized study. Urology 2007;69(4):675-9.

[35] Daniltchenko DI, Riedl CR, Sachs MD, et al. Longterm benefit of 5-aminolevulinic acid fluorescence assisted transurethral resection of superficial bladder cancer: 5year results of a prospective randomized study. J Urol 2005;174(6):2129-33, discussion 33.

[36] Babjuk M, Soukup V, Petrik R, Jirsa M, Dvoracek J. 5-aminolaevulinic acid-induced fluorescence cystoscopy during transurethral resection reduces the risk of recurrence in stage $\mathrm{Ta} / \mathrm{T} 1$ bladder cancer. BJU International 2005;96(6):798-802.

[37] Denzinger S, Wieland WF, Otto W, Filbeck T, Knuechel $\mathrm{R}$, Burger M. Does photodynamic transurethral resection of bladder tumour improve the outcome of initial T1 high-grade bladder cancer? A long-term follow-up of a randomized study. BJU International 2008;101(5):566-9.

[38] Lerner SP, Goh A. Novel endoscopic diagnosis for bladder cancer. Cancer 2015;121(2):169-78.

[39] Herr HW, Donat SM. A comparison of white-light cystoscopy and narrow-band imaging cystoscopy to detect bladder tumour recurrences. BJU International 2008;102(9):1111-4.

[40] Herr HW, Donat SM. Reduced bladder tumour recurrence rate associated with narrow-band imaging surveillance cystoscopy. BJU international 2011;107(3):396-8.

[41] Zheng C, Lv Y, Zhong Q, Wang R, Jiang Q. Narrow band imaging diagnosis of bladder cancer: Systematic review and meta-analysis. BJU International 2012;110(11 Pt B): E680-7.

[42] Herr HW. Randomized Trial of Narrow-band Versus Whitelight Cystoscopy for Restaging (Second-look) Transurethral Resection of Bladder Tumors. Eur Urol 2015;67(4):605-8.

[43] Goh AC, Tresser NJ, Shen SS, Lerner SP. Optical coherence tomography as an adjunct to white light cystoscopy for intravesical real-time imaging and staging of bladder cancer. Urology 2008;72(1):133-7.

[44] Schmidbauer J, Remzi M, Klatte T, et al. Fluorescence cystoscopy with high-resolution optical coherence tomography imaging as an adjunct reduces false-positive findings in the diagnosis of urothelial carcinoma of the bladder. Eur Urol 2009;56(6):914-9.

[45] Chen SP, Liao JC. Confocal laser endomicroscopy of bladder and upper tract urothelial carcinoma: A new era of optical diagnosis? Curr Urol Rep 2014;15(9):437.

[46] Sonn GA, Jones SN, Tarin TV, et al. Optical biopsy of human bladder neoplasia with in vivo confocal laser endomicroscopy. J Urol 2009;182(4):1299-305.

[47] Wu K, Liu JJ, Adams W, et al. Dynamic real-time microscopy of the urinary tract using confocal laser endomicroscopy. Urology 2011;78(1):225-31.

[48] Bach T, Muschter R, Herrmann TR, et al. Technical solutions to improve the management of non-muscle-invasive transitional cell carcinoma: Summary of a European Asso- 
ciation of Urology Section for Uro-Technology (ESUT) and Section for Uro-Oncology (ESOU) expert meeting and current and future perspectives. BJU International 2015;115(1): 14-23.

[49] Ukai R, Kawashita E, Ikeda H. A new technique for transurethral resection of superficial bladder tumor in 1 piece. J Urol 2000;163(3):878-9.

[50] Chen X, Liao J, Chen L, et al. En bloc transurethral resection with 2-micron continuous-wave laser for primary nonmuscle-invasive bladder cancer: A randomized controlled trial. World J Urol 2015;33(7):997.

[51] Yang Y, Wei ZT, Zhang X, Hong BF, Guo G. Transurethral partial cystectomy with continuous wave laser for bladder carcinoma. J Urol 2009;182(1):66-9.

[52] Zhu Y, Jiang X, Zhang J, Chen W, Shi B, Xu Z. Safety and efficacy of holmium laser resection for primary nonmuscle-invasive bladder cancer versus transurethral electroresection: Single-center experience. Urology 2008;72(3):608-12.

[53] Fritsche HM, Otto W, Eder F, et al. Water-jet-aided transurethral dissection of urothelial carcinoma: A prospective clinical study. J Endourol 2011;25(10):1599-603.

[54] DRKS-Deutsches Register Klinischer Studien (German Clinical Trials Register). DRKS-ID: DRKS00004414. "HYbrid knife in bladder cancer resection initially detected by Hexvix based blue-light enhancement (HybridBlue)." Accessed 5/21/2015. Available from: https://drks-neu. uniklinik-freiburg.de/drks_web/navigate.do?navigationId= trial.HTML\&TRIAL_ID=DRKS00004414.

[55] Kim H, Kim M, Kwak C, Kim HH, Ku JH. Prognostic significance of lymphovascular invasion in radical cystectomy on patients with bladder cancer: A systematic review and meta-analysis. PLoS One 2014;9(2):e89259.

[56] Cho KS, Seo HK, Joung JY, et al. Lymphovascular invasion in transurethral resection specimens as predictor of progression and metastasis in patients with newly diagnosed $\mathrm{T} 1$ bladder urothelial cancer. J Urol 2009;182(6):2625-30.

[57] Branchereau J, Larue S, Vayleux B, Karam G, Bouchot O, Rigaud J. Prognostic value of the lymphovascular invasion in high-grade stage pT1 bladder cancer. Clin Genitourin Cancer 2013;11(2):182-8

[58] Streeper NM, Simons CM, Konety BR, et al. The significance of lymphovascular invasion in transurethral resection of bladder tumour and cystectomy specimens on the survival of patients with urothelial bladder cancer. BJU International 2009;103(4):475-9

[59] Martin-Doyle W, Leow JJ, Orsola A, Chang SL, Bellmunt J. Improving Selection Criteria for Early Cystectomy in High-Grade T1 Bladder Cancer: A Meta-Analysis of 15,215 Patients. J Clin Oncol 2015;33(6):643-50.

[60] Porten SP, Willis D, Kamat AM. Variant histology: Role in management and prognosis of nonmuscle invasive bladder cancer. Curr Opin Urol 2014;24(5):517-23.

[61] Wasco MJ, Daignault S, Zhang Y, et al. Urothelial carcinoma with divergent histologic differentiation (mixed histologic features) predicts the presence of locally advanced bladder cancer when detected at transurethral resection. Urology 2007;70(1):69-74.

[62] Ploeg M, Aben KK, Hulsbergen-van de Kaa CA, Schoenberg MP, Witjes JA, Kiemeney LA. Clinical epidemiology of nonurothelial bladder cancer: Analysis of the Netherlands Cancer Registry. J Urol 2010;183(3):915-20.

[63] Shapur NK, Katz R, Pode D, et al. Is radical cystectomy mandatory in every patient with variant histology of bladder cancer. Rare Tumors 2011;3(2):e22.
[64] Fernandez-Gomez J, Madero R, Solsona E, et al. Predicting nonmuscle invasive bladder cancer recurrence and progression in patients treated with bacillus CalmetteGuerin: The CUETO scoring model. J Urol 2009;182(5): 2195-203.

[65] Fernandez-Gomez J, Solsona E, Unda M, et al. Prognostic factors in patients with non-muscle-invasive bladder cancer treated with bacillus Calmette-Guerin: Multivariate analysis of data from four randomized CUETO trials. Eur Urol 2008;53(5):992-1001.

[66] Xylinas E, Kent M, Kluth L, et al. Accuracy of the EORTC risk tables and of the CUETO scoring model to predict outcomes in non-muscle-invasive urothelial carcinoma of the bladder. Br J Cancer 2013;109(6):1460-6.

[67] van Rhijn BW, Liu L, Vis AN, et al. Prognostic value of molecular markers, sub-stage and European Organisation for the Research and Treatment of Cancer risk scores in primary $\mathrm{T} 1$ bladder cancer. BJU International 2012;110(8):1169-76.

[68] Fernandez-Gomez J, Madero R, Solsona E, et al. The EORTC tables overestimate the risk of recurrence and progression in patients with non-muscle-invasive bladder cancer treated with bacillus Calmette-Guerin: External validation of the EORTC risk tables. Eur Urol 2011; 60(3):423-30.

[69] Shariat SF, Zippe C, Ludecke G, et al. Nomograms including nuclear matrix protein 22 for prediction of disease recurrence and progression in patients with Ta, T1 or CIS transitional cell carcinoma of the bladder. J Urol 2005; 173(5):1518-25.

[70] Younes M, Sussman J, True LD. The usefulness of the level of the muscularis mucosae in the staging of invasive transitional cell carcinoma of the urinary bladder. Cancer 1990;66(3):543-8.

[71] Orsola A, Trias I, Raventos CX, et al. Initial high-grade T1 urothelial cell carcinoma: Feasibility and prognostic significance of lamina propria invasion microstaging $(\mathrm{T} 1 \mathrm{a} / \mathrm{b} / \mathrm{c})$ in BCG-treated and BCG-non-treated patients. Eur Urol 2005;48(2):231-8; discussion 8.

[72] Hermann GG, Horn T, Steven K. The influence of the level of lamina propria invasion and the prevalence of p 53 nuclear accumulation on survival in stage $\mathrm{T} 1$ transitional cell bladder cancer. J Urol 1998;159(1):91-4.

[73] Bernardini S, Billerey C, Martin M, Adessi GL, Wallerand $\mathrm{H}$, Bittard $\mathrm{H}$. The predictive value of muscularis mucosae invasion and $\mathrm{p} 53$ over expression on progression of stage $\mathrm{T} 1$ bladder carcinoma. J Urol 2001;165(1):42-6; discussion 6.

[74] Angulo JC, Lopez JI, Grignon DJ, Sanchez-Chapado M Muscularis mucosa differentiates two populations with different prognosis in stage T1 bladder cancer. Urology 1995;45(1):47-53

[75] Faivre d'Arcier B, Celhay O, Safsaf A, et al. [T1 bladder carcinoma: Prognostic value of the muscularis mucosae invasion (T1a/T1b). A multicenter study by the French Urological Association (CCAFU)]. Prog Urol 2010; 20(6):440-9.

[76] Cheng L, Neumann RM, Weaver AL, Spotts BE, Bostwick DG. Predicting cancer progression in patients with stage T1 bladder carcinoma. J Clin Oncol 1999;17(10): 3182-7.

[77] Roupret M, Seisen T, Comperat E, et al. Prognostic interest in discriminating muscularis mucosa invasion (T1a vs T1b) in nonmuscle invasive bladder carcinoma: French national multicenter study with central pathology review. J Urol 2013;189(6):2069-76. 
[78] van Rhijn BW, Burger M, Lotan Y, et al. Recurrence and progression of disease in non-muscle-invasive bladder cancer: From epidemiology to treatment strategy. Eur Urol 2009;56(3):430-42.

[79] van der Aa MN, van Leenders GJ, Steyerberg EW, et al. A new system for substaging pT1 papillary bladder cancer: A prognostic evaluation. Hum Pathol 2005;36(9):981-6.

[80] van Rhijn BW, van der Kwast TH, Alkhateeb SS, et al. A new and highly prognostic system to discern $\mathrm{T} 1$ bladder cancer substage. Eur Urol 2012;61(2):378-84.

[81] Shariat SF, Tokunaga H, Zhou J, et al. p53, p21, pRB, and p16 expression predict clinical outcome in cystectomy with bladder cancer. J Clin Oncol 2004;22(6):1014-24.

[82] Tokunaga H, Shariat SF, Green AE, et al. Correlation of immunohistochemical molecular staging of bladder biopsies and radical cystectomy specimens. Int $\mathbf{J}$ Radiat Oncol Biol Phys 2001;51(1):16-22.

[83] Shariat SF, Zlotta AR, Ashfaq R, Sagalowsky AI, Lotan Y. Cooperative effect of cell-cycle regulators expression on bladder cancer development and biologic aggressiveness. Mod Pathol 2007;20(4):445-59.

[84] Shariat SF, Bolenz C, Godoy G, et al. Predictive value of combined immunohistochemical markers in patients with pT1 urothelial carcinoma at radical cystectomy. J Urol 2009;182(1):78-84; discussion

[85] Dalbagni G, Parekh DJ, Ben-Porat L, Potenzoni M, Herr HW, Reuter VE. Prospective evaluation of p53 as a prognostic marker in $\mathrm{T} 1$ transitional cell carcinoma of the bladder. BJU International 2007;99(2):281-5.

[86] Fristrup N, Birkenkamp-Demtroder K, Reinert T, et al. Multicenter validation of cyclin D1, MCM7, TRIM29, and UBE2C as prognostic protein markers in non-muscleinvasive bladder cancer. Am J Pathol 2013;182(2):339-49.

[87] Dyrskjot L, Zieger K, Real FX, et al. Gene expression signatures predict outcome in non-muscle-invasive bladder carcinoma: A multicenter validation study. Clin Cancer Res 2007;13(12):3545-51.

[88] Descotes F, Dessen P, Bringuier PP, et al. Microarray gene expression profiling and analysis of bladder cancer supports the sub-classification of T1 tumours into T1a and T1b stages. BJU International 2014;113(2):333-42.

[89] Alvarez-Mugica M, Cebrian V, Fernandez-Gomez JM, Fresno F, Escaf S, Sanchez-Carbayo M. Myopodin methylation is associated with clinical outcome in patients with T1G3 bladder cancer. J Urol 2010;184(4):1507-13.

[90] Kandimalla R, van Tilborg AA, Kompier LC, et al. Genomewide analysis of $\mathrm{CpG}$ island methylation in bladder cancer identified TBX2, TBX3, GATA2, and ZIC4 as pTa-specific prognostic markers. Eur Urol 2012;61(6):1245-56.

[91] Patschan O, Sjodahl G, Chebil G, et al. A Molecular Pathologic Framework for Risk Stratification of Stage T1 Urothelial Carcinoma. Eur Urol. 2015 Mar 11. S03022838(15)00183-9.

[92] Lindgren D, Sjodahl G, Lauss $M$, et al. Integrated genomic and gene expression profiling identifies two major genomic circuits in urothelial carcinoma. PLoS One 2012; 7(6):e38863.

[93] Sjodahl G, Lovgren K, Lauss M, et al. Toward a molecular pathologic classification of urothelial carcinoma. Am J Pathol 2013;183(3):681-91.

[94] Sjodahl G, Lauss M, Lovgren K, et al. A molecular taxonomy for urothelial carcinoma. Clin Cancer Res 2012; 18(12):3377-86.

[95] Sylvester RJ, Oosterlinck W, van der Meijden AP. A single immediate postoperative instillation of chemotherapy decreases the risk of recurrence in patients with stage Ta T1 bladder cancer: A meta-analysis of published results of randomized clinical trials. J Urol 2004;171(6 Pt 1):2186-90, quiz 435.

[96] Abern MR, Owusu RA, Anderson MR, Rampersaud EN, Inman BA. Perioperative intravesical chemotherapy in non-muscle-invasive bladder cancer: A systematic review and meta-analysis. J Natl Compr Canc Netw 2013;11(4): 477-84.

[97] Gudjonsson S, Adell L, Merdasa F, et al. Should all patients with non-muscle-invasive bladder cancer receive early intravesical chemotherapy after transurethral resection? The results of a prospective randomised multicentre study. Eur Urol 2009;55(4):773-80.

[98] Kowalik C, Gee JR, Sorcini A, Moinzadeh A, Canes D. Underutilization of immediate intravesical chemotherapy following TURBT: Results from NSQIP. Can J Urol 2014;21(3):7266-70.

[99] Madeb R, Golijanin D, Noyes K, et al. Treatment of nonmuscle invading bladder cancer: Do physicians in the United States practice evidence based medicine? The use and economic implications of intravesical chemotherapy after transurethral resection of bladder tumors. Cancer 2009; 115(12):2660-70.

[100] Bohle A, Bock PR. Intravesical bacille Calmette-Guerin versus mitomycin $\mathrm{C}$ in superficial bladder cancer: Formal meta-analysis of comparative studies on tumor progression. Urology 2004;63(4):682-6; discussion 6-7.

[101] Han RF, Pan JG. Can intravesical bacillus CalmetteGuerin reduce recurrence in patients with superficial bladder cancer? A meta-analysis of randomized trials. Urology 2006;67(6):1216-23.

[102] Malmstrom PU, Sylvester RJ, Crawford DE, et al. An individual patient data meta-analysis of the long-term outcome of randomised studies comparing intravesical mitomycin $\mathrm{C}$ versus bacillus Calmette-Guerin for non-muscle-invasive bladder cancer. Eur Urol 2009;56(2):247-56.

[103] Shelley MD, Kynaston H, Court J, et al. A systematic review of intravesical bacillus Calmette-Guerin plus transurethral resection vs transurethral resection alone in Ta and T1 bladder cancer. BJU International 2001;88(3):209-16.

[104] Shelley MD, Wilt TJ, Court J, Coles B, Kynaston H, Mason MD. Intravesical bacillus Calmette-Guerin is superior to mitomycin $\mathrm{C}$ in reducing tumour recurrence in high-risk superficial bladder cancer: A meta-analysis of randomized trials. BJU International 2004;93(4):485-90.

[105] Bohle A, Jocham D, Bock PR. Intravesical bacillus Calmette-Guerin versus mitomycin $\mathrm{C}$ for superficial bladder cancer: A formal meta-analysis of comparative studies on recurrence and toxicity. J Urol 2003;169(1):90-5.

[106] Sylvester RJ, van der MA, Lamm DL. Intravesical bacillus Calmette-Guerin reduces the risk of progression in patients with superficial bladder cancer: A meta-analysis of the published results of randomized clinical trials. J Urol 2002;168(5):1964-70.

[107] Nieder AM, Brausi M, Lamm D, et al. Management of stage T1 tumors of the bladder: International Consensus Panel. Urology 2005;66(6 Suppl 1):108-25.

[108] Ehdaie B, Sylvester R, Herr HW. Maintenance bacillus Calmette-Guerin treatment of non-muscle-invasive bladder cancer: A critical evaluation of the evidence. Eur Urol 2013;64(4):579-85.

[109] Lamm DL, Blumenstein BA, Crissman JD, et al. Maintenance bacillus Calmette-Guerin immunotherapy for recurrent TA, T1 and carcinoma in situ transitional cell car- 
cinoma of the bladder: A randomized Southwest Oncology Group Study. J Urol 2000;163(4):1124-9.

[110] Oddens J, Brausi M, Sylvester R, et al. Final results of an EORTC-GU cancers group randomized study of maintenance bacillus Calmette-Guerin in intermediate- and high-risk Ta, T1 papillary carcinoma of the urinary bladder: One-third dose versus full dose and 1 year versus 3 years of maintenance. Eur Urol 2013;63(3):462-72.

[111] Martinez-Pineiro L, Portillo JA, Fernandez JM, et al. Maintenance Therapy with 3-monthly Bacillus Calmette-Guerin for 3 Years is Not Superior to Standard Induction Therapy in High-risk Non-muscle-invasive Urothelial Bladder Carcinoma: Final Results of Randomised CUETO Study 98013. Eur Urol 2015;68(2):256-62.

[112] Herr HW, Dalbagni G, Donat SM. Bacillus Calmette-Guerin without maintenance therapy for high-risk non-muscleinvasive bladder cancer. Eur Urol 2011;60(1):32-6.

[113] Guzzo TJ, Magheli A, Bivalacqua TJ, et al. Pathological upstaging during radical cystectomy is associated with worse recurrence-free survival in patients with bacillus Calmette-Guerin-refractory bladder cancer. Urology 2009;74(6):1276-80

[114] Denzinger S, Fritsche HM, Otto W, Blana A, Wieland WF, Burger M. Early versus deferred cystectomy for initial highrisk pT1G3 urothelial carcinoma of the bladder: Do risk factors define feasibility of bladder-sparing approach? Eur Urol 2008;53(1):146-52.

[115] Herr HW, Sogani PC. Does early cystectomy improve the survival of patients with high risk superficial bladder tumors? J Urol 2001;166(4):1296-9.

[116] Raj GV, Herr H, Serio AM, et al. Treatment paradigm shift may improve survival of patients with high risk superficial bladder cancer. J Urol 2007;177(4):1283-6; discussion 6.

[117] De Berardinis E, Busetto GM, Antonini G, Giovannone R, Gentile V. T1G3 high-risk NMIBC (non-muscle invasive bladder cancer): Conservative treatment versus immediate cystectomy. Int Urol Nephrol 2011;43(4):1047-57.

[118] Hautmann RE, Volkmer BG, Gust K. Quantification of the survival benefit of early versus deferred cystectomy in highrisk non-muscle invasive bladder cancer (T1 G3). World J Urol 2009;27(3):347-51.

[119] Lambert EH, Pierorazio PM, Olsson CA, Benson MC, McKiernan JM, Poon S. The increasing use of intravesical therapies for stage $\mathrm{T} 1$ bladder cancer coincides with decreasing survival after cystectomy. BJU International 2007;100(1):33-6.

[120] Wiesner C, Pfitzenmaier J, Faldum A, Gillitzer R, Melchior SW, Thuroff JW. Lymph node metastases in non-muscle invasive bladder cancer are correlated with the number of transurethral resections and tumour upstaging at radical cystectomy. BJU International 2005;95(3):301-5.

[121] Shabsigh A, Korets R, Vora KC, et al. Defining early morbidity of radical cystectomy for patients with bladder cancer using a standardized reporting methodology. Eur Urol 2009;55(1):164-74.

[122] Harland SJ, Kynaston H, Grigor K, et al. A randomized trial of radical radiotherapy for the management of pT1G3 NXM0 transitional cell carcinoma of the bladder. J Urol 2007;178(3 Pt 1):807-13; discussion 13.

[123] Weiss C, Wolze C, Engehausen DG, et al. Radiochemotherapy after transurethral resection for high-risk $\mathrm{T} 1$ bladder cancer: An alternative to intravesical therapy or early cystectomy? J Clin Oncol 2006;24(15):2318-24.

[124] Knoedler J, Frank I. Organ-sparing surgery in urology: Partial cystectomy. Curr Opin Urol 2015;25(2):111-5.
[125] Holzbeierlein JM, Lopez-Corona E, Bochner BH, et al. Partial cystectomy: A contemporary review of the Memorial Sloan-Kettering Cancer Center experience and recommendations for patient selection. J Urol 2004;172(3):878-81.

[126] Kassouf W, Swanson D, Kamat AM, et al. Partial cystectomy for muscle invasive urothelial carcinoma of the bladder: A contemporary review of the M. D. Anderson Cancer Center experience. J Urol 2006;175(6):2058-62.

[127] Capitanio U, Isbarn H, Shariat SF, et al. Partial cystectomy does not undermine cancer control in appropriately selected patients with urothelial carcinoma of the bladder: A population-based matched analysist. Urology 2009;74(4):858-64.

[128] Knoedler JJ, Boorjian SA, Kim SP, et al. Does partial cystectomy compromise oncologic outcomes for patients with bladder cancer compared to radical cystectomy? A matched case-control analysis. J Urol 2012;188(4):1115-9.

[129] Shelley MD, Jones G, Cleves A, Wilt TJ, Mason MD, Kynaston HG. Intravesical gemcitabine therapy for non-muscle invasive bladder cancer (NMIBC): A systematic review. BJU International 2012;109(4):496-505.

[130] Barlow LJ, McKiernan JM, Benson MC. Long-term survival outcomes with intravesical docetaxel for recurrent nonmuscle invasive bladder cancer after previous bacillus Calmette-Guerin therapy. J Urol 2013;189(3):834-9.

[131] Dinney CP, Fisher MB, Navai N, et al. Phase I trial of intravesical recombinant adenovirus mediated interferon-alpha2b formulated in Syn3 for Bacillus Calmette-Guerin failures in nonmuscle invasive bladder cancer. J Urol 2013;190(3): 850-6.

[132] Weintraub MD, Li QQ, Agarwal PK. Advances in intravesical therapy for the treatment of non-muscle invasive bladder cancer (Review). Mol Clin Oncol 2014;2(5):656-60.

[133] Lammers RJ, Witjes JA, Inman BA, et al. The role of a combined regimen with intravesical chemotherapy and hyperthermia in the management of non-muscleinvasive bladder cancer: A systematic review. Eur Urol 2011;60(1):81-93.

[134] Di Stasi SM, Giannantoni A, Stephen RL, et al. Intravesical electromotive mitomycin $\mathrm{C}$ versus passive transport mitomycin $\mathrm{C}$ for high risk superficial bladder cancer: A prospective randomized study. J Urol 2003;170(3): $777-82$.

[135] Di Stasi SM, Valenti M, Verri C, et al. Electromotive instillation of mitomycin immediately before transurethral resection for patients with primary urothelial non-muscle invasive bladder cancer: A randomised controlled trial. Lancet Oncol 2011;12(9):871-9.

[136] Di Stasi SM, Giannantoni A, Giurioli A, et al. Sequential BCG and electromotive mitomycin versus BCG alone for high-risk superficial bladder cancer: A randomised controlled trial. Lancet Oncol 2006;7(1):43-51.

[137] Kang MR, Yang G, Place RF, et al. Intravesical delivery of small activating RNA formulated into lipid nanoparticles inhibits orthotopic bladder tumor growth. Cancer Res 2012;72(19):5069-79.

[138] Mugabe C, Matsui Y, So AI, et al. In vivo evaluation of mucoadhesive nanoparticulate docetaxel for intravesical treatment of non-muscle-invasive bladder cancer. Clin Cancer Res 2011;17(9):2788-98.

[139] McKiernan JM, Barlow LJ, Laudano MA, Mann MJ, Petrylak DP, Benson MC. A phase I trial of intravesical nanoparticle albumin-bound paclitaxel in the treatment of bacillus Calmette-Guerin refractory nonmuscle invasive bladder cancer. J Urol 2011;186(2):448-51. 